\title{
Early angiographic evaluation after off-pump coronary artery bypass grafting
}

\author{
Jota Nakano, MD, ${ }^{\text {a,b }}$ Hitoshi Okabayashi, MD, PhD, ${ }^{\text {a,c }}$ Hisashi Noma, $\mathrm{PhD},{ }^{\mathrm{d}}$ Tosiya Sato, $\mathrm{PhD},{ }^{\mathrm{d}}$ and \\ Ryuzo Sakata, MD, $\mathrm{PhD}^{\mathrm{b}}$
}

Objectives: One of the potential drawbacks of off-pump coronary artery bypass is reduced patency compared with conventional coronary artery bypass. This study examined the systematic angiographic evaluation after offpump coronary artery bypass.

Methods: Of the 1604 consecutive patients who underwent off-pump coronary artery bypass over 6 years, 1422 $(89 \%)$ who underwent postoperative angiography were analyzed. Generalized estimating equations logistic analyses were used to investigate potential predictors of graft failure (FitzGibbon B or O).

\begin{abstract}
Results: Bilateral internal thoracic arteries were used in $78 \%$ of the patients. The mean number of distal anastomoses was $3.7 \pm 1.2$. The in-hospital mortality rate was $0.4 \%$. Recipient coronary diameter less than $1.5 \mathrm{~mm}$ (odds ratio [OR], 1.62; 95\% confidence interval [CI], 1.24-2.11) was an independent predictor of graft failure, whereas percent stenosis diameter greater than $75 \%$ (OR, $0.71 ; 95 \% \mathrm{CI}, 0.53-0.93)$, sequential graft (OR, 0.69 ; $95 \%$ CI, 0.51-0.94), and left main disease (OR, 0.72; 95\% CI, 0.53-0.96) were protective factors. In the subanalyses for each conduit, percent stenosis diameter was protective against left internal thoracic artery failure (OR, 0.61), whereas smaller recipient coronary diameter was associated with right gastroepiploic artery and saphenous vein graft failure (OR, 2.37 and 2.36, respectively). Left circumflex artery was associated with gastroepiploic artery graft failure, whereas sequential graft was again protective for the gastroepiploic artery (OR, 4.39 and 0.33 , respectively).
\end{abstract}

Conclusions: Smaller coronary diameter would be a predictor of graft failure, whereas percent stenosis diameter greater than $75 \%$, sequential graft, and left main disease would be protective factors for off-pump bypass grafts. (J Thorac Cardiovasc Surg 2013;146:1119-25)

Considerable knowledge has been accumulated since offpump coronary artery bypass (OPCAB) gained resurgent interest among cardiac surgeons. However, contrary to surgeons' expectations, major outcomes have not been demonstrated to be better with OPCAB than with conventional coronary artery bypass (CCAB). ${ }^{1,2}$ Several studies ${ }^{3}$ showed that patients undergoing $\mathrm{OPCAB}$ experienced reintervention more frequently at follow-up than those undergoing CCAB. Reduced patency in OPCAB may, in part, account for the higher rate of reintervention at follow-up, because $\mathrm{OPCAB}$ is a more technically demanding procedure than $\mathrm{CCAB} .{ }^{4} \mathrm{Al}$ though some investigators ${ }^{1}$ reported equivalent patency rates for $\mathrm{OPCAB}$ and $\mathrm{CCAB}, 2$ randomized controlled studies ${ }^{2,5}$

\footnotetext{
From the Department of Cardiovascular Surgery, ${ }^{a}$ Kokura Memorial Hospital, Kokura, Japan; the Department of Cardiovascular Surgery, ${ }^{\mathrm{b}}$ Kyoto University Graduate School of Medicine, Kyoto, Japan; the Department of Cardiovascular Surgery, ${ }^{\mathrm{c}}$ Iwate Medical University, Memorial Heart Center, Iwate, Japan; and the Department of Biostatistics, ${ }^{\mathrm{d}}$ Kyoto University School of Public Health, Kyoto, Japan.

Disclosures: Authors have nothing to disclose with regard to commercial support.

Received for publication June 16, 2012; revisions received July 28, 2012; accepted for publication Aug 23, 2012; available ahead of print Sept 24, 2012.

Address for reprints: Jota Nakano, MD, Kyoto University Graduate School of Medicine, 54 Kawahara-cho, Shogoin, Sakyo-ku, Kyoto 606-8507, Japan (E-mail: jotanakano@gmail.com).

$0022-5223 / \$ 36.00$

Copyright (C) 2013 by The American Association for Thoracic Surgery

http://dx.doi.org/10.1016/j.jtcvs.2012.08.057
}

have shown that $\mathrm{OPCAB}$ was associated with an increased risk of graft failure than CCAB. Shroyer and colleagues ${ }^{5}$ demonstrated that the patency rate of the OPCAB arm was lower than that of the on-pump arm on 12-month angiography, and the 1-year composite adverse outcome rate (death from any cause, nonfatal myocardial infarction, and any reintervention procedure) was higher for OPCAB than for CCAB. Several meta-analyses concerning graft patency also showed similar results. ${ }^{4}$

Graft failure is one of the major determinants of clinical prognosis. ${ }^{6}$ However, the optimal graft choice for OPCAB has not been determined, and, at present, it is derived from extrapolation of the previous findings in $\mathrm{CCAB} .{ }^{7}$ High patency rates of arterial conduits at long-term follow-up have been well described in the literature, and attrition seems to be limited to within a few months after the operation. $^{8}$ Thus, the early patency of off-pump bypass grafts needs to be evaluated. This study was conducted to examine the findings of the systematic angiographic evaluation done after OPCAB surgery to identify predictors of graft failure.

\section{MATERIALS AND METHODS Study Design}

This was a database study based on Kokura Memorial Hospital patients' medical records. The primary objective of this study was to identify the independent predictors of graft failure on the basis of the postoperative 


$$
\begin{aligned}
& \text { Abbreviations and Acronyms } \\
& \begin{aligned}
\text { BITA } & =\text { bilateral internal thoracic artery } \\
\text { CCAB } & =\text { conventional coronary artery bypass } \\
\text { CI } & =\text { confidence interval } \\
\text { LAD } & =\text { left anterior descending } \\
\text { LCx } & =\text { left circumflex } \\
\text { LITA } & =\text { left internal thoracic artery } \\
\text { GEA } & =\text { gastroepiploic artery } \\
\text { GEE } & =\text { generalized estimating equation } \\
\text { MDCT } & =\text { multidetector computed tomography } \\
\text { OPCAB } & \text { off-pump coronary artery bypass } \\
\text { OR } & =\text { odds ratio } \\
\text { RCA } & =\text { right coronary artery } \\
\text { SVG } & =\text { saphenous vein graft }
\end{aligned}
\end{aligned}
$$

angiography. In the subanalyses, risk factors for failure of each conduit were explored. This study was approved by the Kokura Memorial Hospital Institutional Review Board, with patient consent waived.

\section{Patients}

From January 2000 to December 2005 inclusive, 1604 consecutive patients underwent isolated OPCAB by a single surgeon at Kokura Memorial Hospital. Of these, 1521 patients $(95 \%)$ underwent systematic angiographic evaluation by means of catheter-based angiography (1422 patients, $89 \%$ ) or multidetector computed tomography (MDCT; SOMATOM Sensation 16; Siemens AG, Munich, Germany; 99 patients, 6\%) before discharge. Because 16-detector row CT has some limitations (eg, lower spatial and temporal resolution), patients who underwent catheter-based angiography comprised the study cohort. Perioperative data were collected prospectively and entered into the institutional database. The definitions of data concerning baseline characteristics conformed to those reported in the European System for Cardiac Operative Risk Evaluation. ${ }^{9}$ The definitions of perioperative factors were delineated previously. ${ }^{10}$

Target territories were defined as the left anterior descending (LAD) artery, left circumflex (LCx) artery, or right coronary artery (RCA) on the basis of their anatomy. Percent stenosis diameter was qualitatively assessed by the operating surgeon and dichotomized as greater than $75 \%$ or $75 \%$ or less in this study. ${ }^{11}$ Recipient vessel diameter was determined from an assessment at surgery by means of 1.0-, 1.5-, or 2.0-mm probe insertion.

\section{Surgical Technique}

OPCAB was the intended procedure, except for patients with acute myocardial infarction who were in a hemodynamically unstable state even with an intra-aortic balloon pump. There were 77 patients who underwent intended $\mathrm{CCAB}$ during the study period. Approximately half of them were in a hemodynamically unstable condition, even with an intra-aortic balloon pump; the remaining patients had previous cardiac surgery and required cardiopulmonary bypass for resternotomy and exposure. All OP$\mathrm{CAB}$ procedures were performed under general anesthesia with pulmonary artery pressure monitoring. The heart was approached via median sternotomy. Heparin (100 KIU/kg and an additional dose) was administered to achieve and maintain the activated clotting time at more than 250 seconds. Graft selection was based on the following strategies: (1) Patients with significantly stenosed $(\geq 75 \%)$ multivessel disease involving the left coronary arteries received bilateral internal thoracic arteries (BITAs); (2) for the left coronary arteries with less than $75 \%$ stenoses, saphenous vein grafts (SVG) or radial arteries were used as additional conduits; (3) for less than $75 \%$ and $75 \%$ or more stenosed RCAs, SVG and right gastroepiploic arteries (GEAs) were used, respectively. Internal thoracic arteries and GEAs were harvested in a skeletonized fashion using an ultrasonic scalpel (Harmonic Scalpel; Ethicon Endo-Surgery, CVG, Cincinnati, $\mathrm{OH})$ by trained surgeons. Diluted papaverine hydrochloride (1:20) was injected into the arterial conduits from the distal end. The conduits were wrapped in a papaverine-soaked gauze until anastomoses. SVG and radial arteries were dissected using the conventional open harvest technique. SVG was gently dilated by injection of heparin-added blood.

The left internal thoracic artery (LITA) was usually anastomosed to the LAD region, and the right internal thoracic artery (RITA) was anastomosed to the LCx via the transverse sinus. When the RITA was not long enough to reach the LCx system, (1) the proximal portion of the RITA was cut and anastomosed to the side of the LITA graft in a Y-shaped fashion as a composite graft ( $30 \%$ of RITA anastomoses) or (2) the pedicled RITA was directed to the LAD system, whereas the LITA was anastomosed to the LCx system (14\% of RITA anastomoses). The choice of BITA configurations was based on the surgeon's preference. Heart positioning was achieved with the help of deep pericardial sutures, suction-type devices (Octopus system, Medtronic, Inc, Minneapolis, Minn; and Acrobat SUV system, Guidant CorporationCardiac Surgery, Santa Clara, Calif), and table tilting. Of the sequential grafts, the distal anastomosis was done in end-to-side fashion. Side-toside anastomoses were made in a diamond shape for SVGs and in a parallel fashion for the arterial grafts. Endarterectomy was performed if a coronary artery had long, calcified plaque. Proximal anastomoses of SVGs and radial arteries were made under a single tangential clamp. When the ascending aorta was not eligible for clamping, proximal anastomotic devices were applied (Symmetry Aortic Connector System, St Jude Medical, Inc, St Paul, Minn; and PAS-Port System, Cardica, Redwood City, Calif). ${ }^{12}$ Grafts were intraoperatively evaluated with flowmetry (CardioMeds; Medi-Stim, Oslo, Norway) to detect bypass dysfunction, although the data were not recorded in our database. Intraoperative decisions (eg, re-anastomosis) were made on the basis of the results of the flowmetry. Heparin was reversed with a half-reversal dose of protamine sulfate after completion of all anastomoses. Subcutaneous heparin at a dose of $100 \mathrm{KIU} / \mathrm{kg}$ was given twice per day on postoperative days 1 to 4 in every patient to prevent postoperative stroke. ${ }^{12}$ Oral aspirin $(100 \mathrm{mg}$ ) was started on postoperative day 1 and continued thereafter. Other antiplatelets (eg, clopidogrel) were not used.

\section{Angiographic Evaluation}

Catheter-based angiography was performed before discharge in the patients, all of whom provided their written informed consent. Postoperative angiography was performed as routine evaluation and is standard of care in Japan. Patients with cerebrovascular disease, renal dysfunction, or respiratory failure were excluded for clinical reasons ( 83 patients). Most patients underwent angiography within 2 weeks after surgery. The experienced interventional cardiologists who performed angiography reviewed the results. Both native coronary arteries and conduits were selectively visualized, and in at least 2 orthogonal views, the conduit was reviewed and scored on the worst appearance of the proximal anastomosis, body of the conduit, and distal anastomosis according to the FitzGibbon classification. ${ }^{6}$ When grafts could not be selectively intubated, an aortogram or a subclavian arteriogram was obtained. Each anastomosis was analyzed separately. A string sign was recorded as FitzGibbon grade B. A patent graft was defined as a graft without $50 \%$ or greater stenosis (ie, FitzGibbon A).

\section{Statistical Analysis}

Continuous data are expressed as means \pm 1 standard deviation or medians (interquartile range), and categoric variables are expressed as numbers (proportions). Because the graft patency of multiple anastomoses within a patient cannot be assumed to be independent, ${ }^{13}$ generalized estimating equation (GEE) logistic analyses were used to evaluate the influence of the potential predictors (Main Analysis). ${ }^{14}$ An event was defined as FitzGibbon grade B or O. The working correlation matrix was set to 
exchangeable, and the robust variance estimators were adopted for constructing confidence intervals (CIs) of the odds ratios (ORs). Model variables used in the multivariable analyses were selected a priori on the basis of the previous reports. ${ }^{15,16}$ Grafting techniques also were included in the model on the presumption that these were clinically relevant. The following 20 factors were included in the analysis: age ( $>75$ years), sex (female), New York Heart Association classification $(\geq 3)$, recent myocardial infarction (within 90 days), left ventricular ejection fraction $(<50 \%)$, chronic renal failure (creatinine $>200 \mu \mathrm{mol} / \mathrm{L}$ ), hypertension, hypercholesterolemia, diabetes mellitus, left main disease $(\geq 50 \%)$, extracardiac arteriopathy, previous cardiac surgery, emergency, operator's experience (first 100 consecutive cases), percent stenosis diameter $(>75 \%)$, recipient coronary diameter $(<1.5 \mathrm{~mm})$, number of anastomoses (continuous), conduits (LITA, RITA, GEA, SVG, and radial artery), territories (LAD, LCx, and RCA), and grafting techniques (sequential, composite, and endarterectomy). In the subanalyses for each conduit, cases with exceptional anastomoses (eg, GEA-LAD anastomosis) were excluded from the GEE models. Subanalysis for the radial artery graft was not performed because there were only 76 radial artery anastomoses (1.4\% of all anastomoses). All analyses were performed using SAS version 9.2 (SAS Institute, Inc, Cary, NC). All $P$ values quoted are 2-sided.

\section{RESULTS}

\section{Patients' Characteristics and Operative Results}

The patients' baseline and perioperative characteristics are shown in Tables 1 and 2. Univariate analyses for graft occlusion revealed estimates of naïve ORs by the GEEs. The patients' average age was $68 \pm 9$ years; $20 \%$ of the patients were aged more than 75 years $(75 \%$ were male, $25 \%$ were female). Left main disease $50 \%$ or greater was present in $44 \%$ of patients. The mean number of distal anastomoses was $3.7 \pm 1.2$. BITA grafts were used in $78 \%$ of patients, and SVGs were used in $41 \%$ of patients. Sequential grafting was performed in $76 \%$ of patients. Of the 5262 anastomoses, $63 \%$ had proximal stenoses greater than $75 \%$. The recipient coronary diameter was less than $1.5 \mathrm{~mm}$ in $35 \%$ of anastomotic sites. Postoperative morbidity included perioperative myocardial infarction in 33 patients (new Q-wave and creatine kinase-myocardial band $>50 \mathrm{IU} / \mathrm{L}$ ), low output syndrome in 7 patients, new-onset atrial fibrillation in 370 patients, stroke in 8 patients, renal failure necessitating dialysis in 18 patients, and prolonged ventilation ( $>48$ hours) in 42 patients. Operative (within 30 days) and in-hospital mortality were $0.1 \%$ and $0.4 \%$, respectively.

\section{Angiographic Evaluation: Main Analysis}

Table 3 shows the distribution and patency rate for each graft (FitzGibbon A). The patency rates of the LITA and RITA grafts were comparable $(95.6 \%$ and $95.5 \%$, respectively), whereas those of the SVG in the LCx and RCA systems were slightly lower ( $92.4 \%$ and $92.9 \%$, respectively). The patency rate of the GEA grafts when used in the LCx system was markedly low $(86.7 \%)$; there were only 60 anastomoses with this configuration.

By using the GEE logistic model, 4 variables were found to be independent predictors of overall graft fate (ie, failure or patency; Table 4). Recipient coronary diameter less than
TABLE 1. Preoperative characteristics

\begin{tabular}{|c|c|c|c|c|}
\hline \multirow[b]{2}{*}{ Variable } & \multirow{2}{*}{$\begin{array}{c}\text { Total, } \mathrm{N}=1422 \\
\text { No. }(\%)\end{array}$} & \multicolumn{3}{|c|}{ Univariate analysis* } \\
\hline & & OR & $95 \%$ CI & $\begin{array}{c}P \\
\text { value }\end{array}$ \\
\hline Age (y) & $68 \pm 9$ & & & \\
\hline Age $>75 y$ & $290(20)$ & 1.39 & $1.02-1.90$ & .039 \\
\hline Female sex & $379(25)$ & 1.45 & $1.08-1.95$ & .014 \\
\hline NYHA class $\geq 3$ & $265(19)$ & 0.88 & $0.62-1.25$ & .468 \\
\hline Unstable angina & $318(22)$ & 0.81 & $0.57-1.16$ & .256 \\
\hline Emergency & $109(8)$ & 0.86 & $0.50-1.48$ & .582 \\
\hline Previous MI & $614(43)$ & 0.99 & $0.75-1.30$ & .924 \\
\hline Recent MI (<90 d) & $140(10)$ & 1.21 & $0.76-1.82$ & .371 \\
\hline \multicolumn{5}{|l|}{ LV dysfunction } \\
\hline Fair $(\mathrm{LVEF}>50 \%)$ & $1093(77)$ & Reference & & \\
\hline $\begin{array}{l}\text { Moderate } \\
\quad(\text { LVEF } 30 \%-50 \%)\end{array}$ & $299(21)$ & 0.75 & $0.52-1.07$ & .113 \\
\hline Poor $($ LVEF < 30\%) & $30(2)$ & 0.93 & $0.38-2.25$ & .865 \\
\hline \multicolumn{5}{|l|}{ Diseased vessels } \\
\hline 1- or 2-vessel disease & $450(32)$ & Reference & & \\
\hline 3-vessel disease & $972(68)$ & 1.20 & $0.58-2.48$ & .518 \\
\hline Left main disease & $619(44)$ & 0.69 & $0.51-0.91$ & .010 \\
\hline Previous PCI & $619(44)$ & 0.97 & $0.73-1.28$ & .815 \\
\hline Previous cardiac surgery & $33(2)$ & 1.64 & $0.81-3.35$ & .172 \\
\hline $\begin{array}{l}\text { CRF (creatinine } \\
\quad>200 \mu \mathrm{mol} / \mathrm{L} \text { ) }\end{array}$ & $94(7)$ & 0.61 & $0.31-1.19$ & .145 \\
\hline ESRF on dialysis & $70(5)$ & & & \\
\hline Diabetes mellitus & $659(46)$ & 1.04 & $0.79-1.38$ & .771 \\
\hline Taking insulin & $163(11)$ & & & \\
\hline Hypertension & $951(67)$ & 0.93 & $0.70-1.23$ & .601 \\
\hline Hypercholesterolemia & $793(56)$ & 1.07 & $0.81-1.42$ & .635 \\
\hline COPD & $36(3)$ & 1.16 & $0.60-2.26$ & .658 \\
\hline Extracardiac arteriopathy & $296(21)$ & 0.85 & $0.61-1.19$ & .350 \\
\hline CVA & $240(17)$ & 1.04 & $0.71-1.51$ & .837 \\
\hline
\end{tabular}

$O R$, Odds ratio; $C I$, confidence interval; NYHA, New York Heart Association; $M I$, myocardial infarction; $L V$, left ventricle; $L V E F$, left ventricular ejection fraction; $P C I$, percutaneous coronary intervention; $C R F$, chronic renal failure; $E S R F$, end-stage renal failure; $C O P D$, chronic obstructive pulmonary disease; $C V A$, cerebrovascular accident. *Univariate analysis for graft occlusion. Estimates of naïve ORs by the GEEs.

$1.5 \mathrm{~mm}$ was a risk factor for graft failure (OR, $1.62 ; 95 \% \mathrm{CI}$, 1.24-2.11), whereas percent stenosis diameter greater than $75 \%$ (OR, 0.71; 95\% CI, 0.53-0.93), sequential graft (OR, $0.69 ; 95 \%$ CI, 0.51-0.94), and left main disease (OR, 0.72; $95 \%$ CI, 0.53-0.96) protected against graft failure. Other baseline variables, such as LVEF and diabetes mellitus, or operative factors such as type of conduit and target territory, were not associated with graft failure in the multivariable analysis. Although the patency rate of those patients with coronary endarterectomy was relatively low $(82.1 \%)$, this technique was not associated with graft failure.

\section{Angiographic Evaluation: Subanalysis for Each Conduit}

For LITA grafts, percent stenosis diameter greater than $75 \%$ was the only predictor of patency (OR, $0.61 ; 95 \%$ CI, 0.40-0.94; Table 5). None of the variables were 
TABLE 2. Perioperative characteristics

\begin{tabular}{|c|c|c|c|c|}
\hline \multirow[b]{2}{*}{ Variable } & \multirow{2}{*}{$\begin{array}{c}\text { Total, } N=1422 \\
\text { No. }(\%)\end{array}$} & \multicolumn{3}{|c|}{ Univariate analysis* } \\
\hline & & OR & $95 \%$ CI & $\begin{array}{c}P \\
\text { value }\end{array}$ \\
\hline First 100 cases & $90(6)$ & 0.92 & $0.53-1.60$ & .765 \\
\hline No. of anastomoses & $3.7 \pm 1.2$ & 1.01 & $0.88-1.16$ & .853 \\
\hline $\begin{array}{l}\text { Incomplete } \\
\text { revascularization }\end{array}$ & $187(13)$ & 0.89 & $0.57-1.39$ & .607 \\
\hline Conversion to $\mathrm{CCAB}$ & $4(0.3)$ & - & - & - \\
\hline Operation time (min) & $288 \pm 72$ & 1.13 & $1.01-1.27$ & .032 \\
\hline \multicolumn{5}{|l|}{ Conduit } \\
\hline LITA & $1365(96)$ & Reference & & \\
\hline RITA & $1083(76)$ & 1.04 & $0.73-1.48$ & .836 \\
\hline GEA & $476(33)$ & 1.27 & $0.82-1.95$ & .285 \\
\hline SVG & $586(41)$ & 1.68 & $1.17-2.43$ & .005 \\
\hline Radial artery & $47(3)$ & 0.95 & $0.29-3.11$ & .936 \\
\hline \multicolumn{5}{|l|}{ Territory } \\
\hline LAD & $1400(98)$ & Reference & & \\
\hline $\mathrm{LCx}$ & $1237(87)$ & 1.20 & $0.87-1.65$ & .273 \\
\hline RCA & $962(68)$ & 1.39 & $0.99-1.94$ & .056 \\
\hline \multicolumn{5}{|l|}{ Grafting technique } \\
\hline Sequential graft & $1076(76)$ & 0.80 & $0.61-1.04$ & .099 \\
\hline Composite graft & 345 (24) & 1.36 & $0.91-2.04$ & .128 \\
\hline Endarterectomy & $31(2)$ & 2.23 & $0.65-7.68$ & .202 \\
\hline $\begin{array}{l}\text { Proximal anastomotic } \\
\text { devices }\end{array}$ & $83(5)$ & 0.46 & $0.20-1.06$ & .068 \\
\hline \multicolumn{5}{|l|}{$\begin{array}{l}\text { Recipient coronary } \\
\qquad(\mathrm{N}=5262)\end{array}$} \\
\hline Stenosis $>75 \%$ & $3293(63)$ & 0.73 & $0.56-0.95$ & .019 \\
\hline Diameter $<1.5 \mathrm{~mm}$ & $1860(35)$ & 1.61 & $1.25-2.09$ & $<.001$ \\
\hline$<1.0 \mathrm{~mm}$ & $21(0.4)$ & & & \\
\hline $1.0 \mathrm{~mm}$ & $2462(47)$ & & & \\
\hline $1.5 \mathrm{~mm}$ & $2613(50)$ & & & \\
\hline$>1.5 \mathrm{~mm}$ & $166(3)$ & & & \\
\hline $\begin{array}{c}\text { Max CK-MB IU/L } \\
(\mathrm{N}=1402)\end{array}$ & $13(8.6-24) \dagger$ & 1.02 & $1.00-1.03$ & .026 \\
\hline CK-MB > $50 \mathrm{IU} / \mathrm{L}$ & $148(10)$ & 1.66 & $1.12-2.47$ & .012 \\
\hline \multicolumn{5}{|l|}{ Mortality } \\
\hline Operative (within $30 \mathrm{~d}$ ) & $1(0.1)$ & & & \\
\hline In-hospital & $5(0.4)$ & & & \\
\hline
\end{tabular}

$O R$, Odds ratio; $C I$, confidence interval; $C C A B$, conventional coronary artery bypass; LITA, left internal thoracic artery; RITA, right internal thoracic artery; GEA, gastroepiploic artery; $S V G$, saphenous vein graft; $L A D$, left anterior descending; $L C x$, left circumflex; $R C A$, right coronary artery; $C K-M B$, creatine kinase-myocardial band isozyme. *Univariate analysis for graft occlusion. Estimates of naive ORs by the GEEs. †Median (interquartile range).

associated with RITA graft failure. Smaller recipient coronary diameter $(<1.5 \mathrm{~mm})$ showed a trend to correlate with GEA graft and SVG failure (OR, 2.37 and 2.36; 95\% CI, 1.08-5.20 and 1.32-4.19, respectively). Of note, the LCx system was a predictor of GEA graft failure (OR, $4.39 ; 95 \%$ CI, 1.66-11.61), whereas sequential graft was a protective factor for GEA graft patency (OR, 0.33; 95\% CI, 0.15-0.70).

\section{Patients Who Did Not Undergo Angiography}

Among the patients who did not undergo postoperative angiography, all but 1 had no sign of ischemia during the
TABLE 3. Graft distribution and patency rate

\begin{tabular}{|c|c|c|c|c|c|c|}
\hline \multirow[b]{2}{*}{ Conduit } & \multirow[b]{2}{*}{ Territory } & \multirow[b]{2}{*}{ Total no. } & \multicolumn{3}{|c|}{ FitzGibbon } & \multirow[b]{2}{*}{ Patency rate $\dagger$} \\
\hline & & & A & B* & O & \\
\hline \multirow[t]{4}{*}{ LITA } & LAD & 1925 & 1841 & $70(13)$ & 14 & $95.6 \%$ \\
\hline & LCx & 227 & 218 & $7(1)$ & 2 & $96.0 \%$ \\
\hline & RCA & 4 & 2 & 0 & 2 & $50.0 \%$ \\
\hline & Total & 2156 & 2061 & 77 (14) & 18 & $95.6 \%$ \\
\hline \multirow[t]{4}{*}{ RITA } & LAD & 231 & 220 & $10(1)$ & 1 & $95.2 \%$ \\
\hline & LCx & 1145 & 1093 & $31(3)$ & 21 & $95.5 \%$ \\
\hline & RCA & 37 & 36 & 1 & 0 & $97.3 \%$ \\
\hline & Total & 1413 & 1349 & $42(4)$ & 22 & $95.5 \%$ \\
\hline \multirow[t]{4}{*}{ GEA } & LAD & 7 & 7 & 0 & 0 & $100 \%$ \\
\hline & LCx & 60 & 52 & 2 & 6 & $86.7 \%$ \\
\hline & RCA & 585 & 557 & $16(3)$ & 12 & $95.2 \%$ \\
\hline & Total & 652 & 616 & $18(3)$ & 18 & $94.5 \%$ \\
\hline \multirow[t]{4}{*}{ SVG } & LAD & 88 & 84 & 3 & 1 & $95.5 \%$ \\
\hline & LCx & 288 & 266 & 4 & 18 & $92.4 \%$ \\
\hline & RCA & 588 & 546 & $16(1)$ & 26 & $92.9 \%$ \\
\hline & Total & 964 & 896 & $23(1)$ & 45 & $92.9 \%$ \\
\hline \multirow[t]{4}{*}{ Radial artery } & LAD & 4 & 4 & 0 & 0 & $100 \%$ \\
\hline & LCx & 49 & 48 & 1 & 0 & $98.0 \%$ \\
\hline & RCA & 23 & 21 & 1 & 1 & $91.3 \%$ \\
\hline & Total & 76 & 73 & 2 & 1 & $96.1 \%$ \\
\hline
\end{tabular}

LITA, Left internal thoracic artery; $L A D$, left anterior descending; $L C x$, left circumflex; $R C A$, right coronary artery; RITA, right internal thoracic artery; $G E A$, gastroepiploic artery; $S V G$, saphenous vein graft. *Numbers in parentheses represent string sign. †FitzGibbon A.

hospital stay. One death occurred in a 69-year-old woman. Vasospasm of the radial artery graft was suspected to be the cause.

\section{Postangiography Outcomes}

Eight patients $(0.6 \%)$ experienced complications of postoperative angiography: limb thrombosis in 2 patients, ventricular arrhythmia in 1 patient, dissection of the aorta in 1 patient, transient ischemic attack in 2 patients, and cerebral infarction in 2 patients. The 2 patients with cerebral infarction showed neurologic dysfunction, but all 8 patients were discharged.

Of the 216 patients with at least 1 suboptimal graft (FitzGibbon B or O), 25 underwent repeated interventions as staged procedures (24 percutaneous coronary interventions and 1 surgery) after scintigraphy.

\section{DISCUSSION}

One of the possible drawbacks of OPCAB surgery is reduced patency compared with CCAB. ${ }^{2,4,5}$ Graft failure is relevant to the clinical prognosis of patients undergoing $\mathrm{CCAB},{ }^{6}$ and it is logical to think that this association may fit the OPCAB cohort. Many studies have been published concerning graft patency in $\mathrm{CCAB}$. However, few reports have specifically dealt with this issue in OPCAB surgery. ${ }^{17}$ In addition, the results from these studies should be interpreted cautiously, because few of them took clustering into account, ${ }^{1,17}$ and the findings of most studies were derived from symptom-driven angiography. 
TABLE 4. Multivariable analysis: Predictors of graft occlusion (FitzGibbon B or O)

\begin{tabular}{|c|c|c|c|}
\hline Variable & OR & $\mathbf{9 5} \% \mathrm{CI}$ & $P$ value \\
\hline Age $>75 y$ & 1.37 & $0.98-1.90$ & .064 \\
\hline Female sex & 1.24 & $0.91-1.68$ & .183 \\
\hline NYHA class $\geq 3$ & 0.89 & $0.60-1.35$ & .592 \\
\hline Recent MI (<90 d) & 1.25 & $0.82-1.91$ & .301 \\
\hline $\mathrm{LVEF}<50 \%$ & 0.79 & $0.56-1.12$ & .181 \\
\hline CRF & 0.67 & $0.34-1.33$ & .253 \\
\hline Hypertension & 0.93 & $0.69-1.25$ & .627 \\
\hline Hypercholesterolemia & 1.07 & $0.79-1.44$ & .668 \\
\hline Diabetes mellitus & 1.06 & $0.79-1.40$ & .712 \\
\hline Left main disease & 0.72 & $0.53-0.96$ & .028 \\
\hline Extracardiac arteriopathy & 0.86 & $0.61-1.22$ & .401 \\
\hline Previous cardiac surgery & 1.25 & $0.57-2.75$ & .580 \\
\hline Emergency & 0.88 & $0.48-1.61$ & .683 \\
\hline First 100 cases & 1.00 & $0.58-1.73$ & .995 \\
\hline \multicolumn{4}{|l|}{ Recipient coronary } \\
\hline Stenosis $>75 \%$ & 0.71 & $0.53-0.93$ & .013 \\
\hline Diameter $<1.5 \mathrm{~mm}$ & 1.62 & $1.24-2.11$ & $<.001$ \\
\hline No. of anastomoses & 1.04 & $0.89-1.21$ & .618 \\
\hline \multicolumn{4}{|l|}{ Conduit } \\
\hline LITA & Reference & & \\
\hline RITA & 0.75 & $0.45-1.26$ & .275 \\
\hline GEA & 1.16 & $0.57-2.38$ & .684 \\
\hline SVG & 1.37 & $0.78-2.40$ & .275 \\
\hline Radial artery & 0.70 & $0.20-2.48$ & .579 \\
\hline \multicolumn{4}{|l|}{ Territory } \\
\hline LAD & Reference & & \\
\hline $\mathrm{LCx}$ & 1.06 & $0.69-1.61$ & .805 \\
\hline $\mathrm{RCA}$ & 0.88 & $0.48-1.60$ & .668 \\
\hline \multicolumn{4}{|l|}{ Grafting technique } \\
\hline Sequential graft & 0.69 & $0.51-0.94$ & .018 \\
\hline Composite graft & 1.61 & $0.98-2.62$ & .058 \\
\hline Endarterectomy & 1.96 & $0.62-6.24$ & .254 \\
\hline
\end{tabular}

$O R$, Odds ratio; $C I$, confidence interval; NYHA, New York Heart Association; $M I$, myocardial infarction; $L V E F$, left ventricular ejection fraction; $C R F$, chronic renal failure; LITA, left internal thoracic artery; RITA, right internal thoracic artery; $G E A$, gastroepiploic artery; $S V G$, saphenous vein graft; $L A D$, left anterior descending; $L C x$, left circumflex; $R C A$, right coronary artery.

In 1604 consecutive patients who underwent OPCAB, $89 \%$ received systematic catheter-based angiography before discharge. GEE logistic analysis was performed to identify the independent predictors of graft failure, and percent stenosis diameter $(>75 \%)$, recipient coronary diameter $(<1.5 \mathrm{~mm})$, sequential graft, and left main disease were found to be predictors.

\section{Percent Stenosis Diameter}

When arterial grafts are used to bypass a low-grade stenosis, competitive flow may increase from the native coronary vessel. ${ }^{18}$ Several authors also noted an association between decreased severity of stenosis and frequency of the string sign. ${ }^{11}$ Miwa and colleagues ${ }^{19}$ reported that the string sign of patent radial arteries was a consequence of competitive flow. The current authors and Desai and colleagues ${ }^{15}$ have speculated that arterial remodeling to maintain shear stress against the endothelium in the setting of low flow may lead to graft failure.

\section{Recipient Coronary Diameter}

Desai and colleagues ${ }^{15}$ noted that the distal run-off was strongly correlated with the size of the distal target vessel. Similar to percent stenosis diameter, recipient coronary diameter is deemed to influence the flow through the bypass conduits. Grafting small target vessels may be more technically demanding, especially on the beating heart. On the basis of the results of the subanalysis of each conduit (Table 5), an internal thoracic artery conduit could be expected to have excellent patency for the left coronary arteries even with small target-vessel size.

\section{Sequential Graft}

Sequential graft was revealed to be a determinant of graft patency. The primary advantages of this technique include a higher blood flow through the sequential graft than through the individual graft. ${ }^{20}$ Intraoperative velocity studies showed a higher velocity of blood flow in the sequential graft. ${ }^{21}$ Although a sequential graft may be technically difficult in OPCAB surgery, several authors have reported excellent results. ${ }^{22}$

\section{Left Main Disease}

The reason why left main disease served as a protective factor for graft patency was not identified from this retrospective study. When the study cohort was divided as to the sides of the coronary arteries grafted (left or right), left main disease was associated with graft patency in the left coronary arteries, not in the RCAs (data not shown). This result may imply that left main disease, in addition to percent stenosis diameter, decreased the risk of competitive flow. It is also conceivable that patients who have significant left main disease are good candidates for not only $\mathrm{CCAB}^{23}$ but also OPCAB surgery. However, noncritical, isolated left main stenosis may cause competitive flow. Relationships between graft patency in OPCAB surgery and left main disease (eg, ostial, mid-shaft, and noncritical lesions) need to be evaluated in the future.

\section{Subanalysis: Left Internal Thoracic Artery}

In our subanalyses, less severe percent stenosis diameter was associated with LITA graft failure. Doppler studies suggested that severity of stenosis is associated with flow and size of the LITA graft. ${ }^{18}$ However, adaptive shrinkage of the arterial conduits may be reversible as the native coronary stenosis progresses.

\section{Subanalysis: Gastroepiploic Artery}

Recipient coronary diameter influenced the patency of the GEA. The GEA may be more susceptible to having 
TABLE 5. Subanalysis of each conduit

\begin{tabular}{|c|c|c|c|c|c|c|c|c|c|c|c|c|}
\hline \multirow[b]{2}{*}{ Variable } & \multicolumn{3}{|c|}{ LITA } & \multicolumn{3}{|c|}{ RITA } & \multicolumn{3}{|c|}{ GEA } & \multicolumn{3}{|c|}{ SVG } \\
\hline & OR & $95 \%$ CI & $P$ & OR & $95 \%$ CI & $P$ & OR & $95 \%$ CI & $\boldsymbol{P}$ & OR & $95 \% \mathrm{CI}$ & $P$ \\
\hline \multicolumn{13}{|l|}{ Recipient coronary } \\
\hline Stenosis $>75 \%$ & 0.61 & $0.40-0.94$ & .025 & 0.77 & $0.45-1.31$ & .331 & 0.91 & $0.93-2.11$ & .826 & 0.96 & $0.53-1.73$ & .878 \\
\hline Diameter $<1.5 \mathrm{~mm}$ & 1.14 & $0.71-1.82$ & .591 & 1.65 & $0.98-2.80$ & .061 & 2.37 & $1.08-5.20$ & .032 & 2.36 & $1.32-4.19$ & .004 \\
\hline \multicolumn{13}{|l|}{ Territory } \\
\hline LAD & Reference & & & 1.22 & $0.66-2.25$ & .531 & - & - & - & - & - & - \\
\hline $\mathrm{LCx}$ & 0.85 & $0.37-1.97$ & .706 & Reference & & & 4.39 & $1.66-11.61$ & .003 & 1.25 & $0.70-2.26$ & .449 \\
\hline RCA & - & - & - & - & - & - & Reference & & & Reference & & \\
\hline \multicolumn{13}{|l|}{ Grafting technique } \\
\hline Sequential graft & 0.99 & $0.59-1.67$ & .968 & 0.94 & $0.53-1.69$ & .845 & 0.33 & $0.15-0.70$ & .004 & 0.76 & $0.41-1.40$ & .375 \\
\hline Composite graft & - & - & - & 0.86 & $0.44-1.72$ & .676 & - & - & - & 1.46 & $0.64-3.30$ & .369 \\
\hline Endarterectomy & - & - & - & - & - & - & - & - & - & 3.45 & $0.75-15.88$ & .111 \\
\hline
\end{tabular}

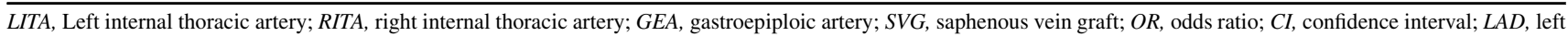
anterior descending; $L C x$, left circumflex; $R C A$, right coronary artery.

a contractile response in the low-flow situation than the LITA because of their different histologic characteristics. ${ }^{24}$ We preferentially used the GEA grafts for the RCA system with severe stenosis $(>75 \%)$. This may partly explain the reason why recipient coronary diameter, not percent stenosis diameter, influenced GEA patency. On the other hand, a sequential graft seems advantageous with GEA grafts, as shown in the subanalysis (Table 5). This technique may help increase the graft flow.

The LCx system was associated with graft failure. In our experience, by harvesting in a skeletonized fashion, the GEA grafts could reach the LCx in some cases. The higher failure rate of this configuration may be attributed to spasm of the distal portion of the GEA and tension on the graft. We have abandoned this configuration and adopted the SVG and the RITA for mild and severe lesions of the LCx, respectively.

\section{Subanalysis: Saphenous Vein Graft}

SVG failure was associated with smaller recipient coronary diameter. Goldman and colleagues ${ }^{16}$ reported that the smaller diameter of the recipient vessel was a determinant in both early and long-term vein graft patency. Schwartz and colleagues ${ }^{25}$ noted that the SVG was a risk factor for graft occlusion in the Bypass Angioplasty Revascularization Investigation study, whereas the type of conduit was not associated with graft patency in our series. This discordance may be, in part, ascribed to routine heparin use. ${ }^{12}$ Presumably, an increase in coagulability may account for the early graft occlusion. Therefore, we believe that high-risk patients may require aggressive anticoagulation in addition to antiplatelet therapy after OPCAB.

In 83 cases, proximal anastomotic devices were applied. We previously reported that the early patency rate of these SVGs was $100 \% .{ }^{12}$ As a result, these devices did not adversely influence the graft patency in this study.

\section{Study Limitations}

First, percent stenosis diameter was derived from qualitative assessment by one observer. Other investigators drew conclusions similar to ours in that small target vessel size adversely affected graft patency, although the size of the target vessel was derived from single-observer visual assessment at the time of patient enrollment and not quantitative angiography. ${ }^{15}$ Second, all procedures were performed by a single surgeon, and the results of the angiography were derived from the OPCAB surgery on the basis of our grafting strategy, limiting the generalizability of these results. Third, catheter-based angiography was performed in only $89 \%$ of the consecutive patients, because MDCT took the place of catheter-based angiography after 2 patients experienced cerebral infarction. Because 16-detector row CT has some limitations (eg, lower spatial and temporal resolution), patients who underwent MDCT were omitted from the study cohort. In addition, the angiography results were read by several cardiologists. Fourth, we did not evaluate longterm patency rates. However, we agree with Goldman and colleagues ${ }^{16}$ in that initial patency at 1 week after surgery is an important predictor of long-term graft patency. Fifth, we could not compare the angiographic results between OP$\mathrm{CAB}$ and on-pump coronary artery bypass grafting, because only 77 patients underwent on-pump coronary artery bypass grafting in Kokura Memorial Hospital (Kokura, Japan) during the study period. Sixth, we cannot reach any conclusions regarding the radial artery graft because of the small sample size. Finally, the quality of the recipient coronary arteries, the size of the conduits, and the flow data were not recorded in our database. Despite these limitations, the findings of this study were derived from the largest angiographic study to date of OPCAB surgery. In addition, the analyses were based on rigorous statistical methodology.

\section{CONCLUSIONS}

Severe percent stenosis diameter and small recipient coronary diameter were associated with graft patency in 
OPCAB surgery. A better patency rate would be expected when anastomosing the LITA to a coronary artery with severe stenosis. Sequential grafting technique could be expected to improve the patency rates of off-pump bypass grafts, especially for the GEA. Patients with significant left main disease may be good candidates for OPCAB surgery.

\section{References}

1. Puskas JD, Williams WH, Mahoney EM, Huber PR, Block PC, Duke PG, et al. Off-pump vs conventional coronary artery bypass grafting: early and 1-year graft patency, cost, and quality-of-life outcomes: a randomized trial. JAMA. 2004;291: 1841-9.

2. Khan NE, De Souza A, Mister R, Flather M, Clague J, Davies S, et al. A randomized comparison of off-pump and on-pump multivessel coronary-artery bypass surgery. N Engl J Med. 2004;350:21-8.

3. Wijeysundera DN, Beattie WS, Djaiani G, Rao V, Borger MA, Karkouti K, et al. Off-pump coronary artery surgery for reducing mortality and morbidity: metaanalysis of randomized and observational studies. J Am Coll Cardiol. 2005;46: 872-82.

4. Parolari A, Alamanni F, Polvani G, Agrifoglio M, Chen YB, Kassem S, et al. Meta-analysis of randomized trials comparing off-pump with on-pump coronary artery bypass graft patency. Ann Thorac Surg. 2005;80:2121-5.

5. Shroyer AL, Grover FL, Hattler B, Collins JF, McDonald GO, Kozora E, et al. On-pump versus off-pump coronary-artery bypass surgery. $N$ Engl $\mathrm{J} \mathrm{Med}$. 2009;361:1827-37.

6. FitzGibbon GM, Kafka HP, Leach AJ, Keon WJ, Hooper GD, Burton JR. Coronary bypass graft fate and patient outcome: angiographic follow-up of 5,065 grafts related to survival and reoperation in 1,388 patients during 25 years. J Am Coll Cardiol. 1996;28:616-26.

7. Buxton BF, Hayward PA, Newcomb AE, Moten S, Seevanayagam S, Gordon I. Choice of conduits for coronary artery bypass grafting: craft or science? Eur $J$ Cardiothorac Surg. 2009;35:658-70.

8. Dion R, Glineur D, Derouck D, Verhelst R, Noirhomme P, El Khoury G, et al. Long-term clinical and angiographic follow-up of sequential internal thoracic artery grafting. Eur J Cardiothorac Surg. 2000;17:407-14.

9. Nashef SA, Roques F, Michel P, Gauducheau E, Lemeshow S, Salamon R. European System for Cardiac Operative Risk Evaluation (EuroSCORE). Eur J Cardiothorac Surg. 1999;16:9-13.

10. Nakano J, Okabayashi H, Hanyu M, Soga Y, Nomoto T, Arai Y, et al. Risk factors for wound infection after off-pump coronary artery bypass grafting: should bilateral internal thoracic arteries be harvested in patients with diabetes? J Thorac Cardiovasc Surg. 2008;135:540-5

11. Manninen HI, Jaakkola P, Suhonen M, Rehnberg S, Vuorenniemi R, Matsi PJ. Angiographic predictors of graft patency and disease progression after coronary artery bypass grafting with arterial and venous grafts. Ann Thorac Surg. 1998;66 1289-94.

12. Kitamura H, Okabayashi H, Hanyu M, Soga Y, Nomoto T, Johno H, et al. Early and midterm patency of the proximal anastomoses of saphenous vein grafts made with a Symmetry Aortic Connector System. J Thorac Cardiovasc Surg. 2005; 130:1028-31.

13. Henderson WG, Moritz T, Goldman S, Copeland J, Souchek J, Zadina K, et al. The statistical analysis of graft patency data in a clinical trial of antiplatelet agents following coronary artery bypass grafting. Control Clin Trials. 1988;9: 189-205.

14. Liang KY, Zeger SL. Longitudinal data-analysis using generalized linearmodels. Biometrika. 1986;73:13-22.

15. Desai ND, Naylor CD, Kiss A, Cohen EA, Feder-Elituv R, Miwa S, et al. Impact of patient and target-vessel characteristics on arterial and venous bypass graft patency: insight from a randomized trial. Circulation. 2007;115:684-91.

16. Goldman S, Zadina K, Moritz T, Ovitt T, Sethi G, Copeland JG, et al. Long-term patency of saphenous vein and left internal mammary artery grafts after coronary artery bypass surgery: results from a Department of Veterans Affairs Cooperative Study. J Am Coll Cardiol. 2004;44:2149-56.

17. Magee MJ, Alexander JH, Hafley G, Ferguson TB Jr, Gibson CM, Harrington RA, et al. Coronary artery bypass graft failure after on-pump and off-pump coronary artery bypass: findings from PREVENT IV. Ann Thorac Surg. 2008;85:494-500.

18. Nasu M, Akasaka T, Okazaki T, Shinkai M, Fujiwara H, Sono J, et al. Postoperative flow characteristics of left internal thoracic artery grafts. Ann Thorac Surg. 1995;59:154-62.

19. Miwa S, Desai N, Koyama T, Chan E, Cohen EA, Fremes SE. Radial artery angiographic string sign: clinical consequences and the role of pharmacologic therapy. Ann Thorac Surg. 2006;81:112-9.

20. Christenson JT, Schmuziger M. Sequential venous bypass grafts: results 10 years later. Ann Thorac Surg. 1997;63:371-6.

21. O'Neill MJ Jr, Wolf PD, O'Neill TK, Montesano RM, Waldhausen JA. A rationale for the use of sequential coronary artery bypass grafts. $J$ Thorac Cardiovasc Surg. 1981;81:686-90.

22. Al-Ruzzeh S, George S, Bustami M, Nakamura K, Khan S, Yacoub M, et al. The early clinical and angiographic outcome of sequential coronary artery bypass grafting with the off-pump technique. J Thorac Cardiovasc Surg. 2002;123: 525-30.

23. Smith CR. Surgery, not percutaneous revascularization, is the preferred strategy for patients with significant left main coronary stenosis. Circulation. 2009;119: 1013-20.

24. He GW, Yang CQ. Comparison among arterial grafts and coronary artery. An attempt at functional classification. J Thorac Cardiovasc Surg. 1995;109: 707-15.

25. Schwartz L, Kip KE, Frye RL, Alderman EL, Schaff HV, Detre KM. Coronary bypass graft patency in patients with diabetes in the Bypass Angioplasty Revascularization Investigation (BARI). Circulation. 2002;106:2652-8. 